\title{
The role of PML in hematopoietic and leukemic stem cell maintenance
}

\author{
Fumio Nakahara $\cdot$ Cary N. Weiss $\cdot$ Keisuke Ito
}

Received: 2 December 2013/Revised: 13 January 2014 / Accepted: 15 January 2014/Published online: 1 February 2014

(C) The Japanese Society of Hematology 2014

\begin{abstract}
The tumor suppressor promyelocytic leukemia (PML) was first identified as a component of PML-RAR $\alpha$ fusion protein, one of the initiating cytogenetic abnormalities in acute promyelocytic leukemia. PML is now known to have diverse functions regulating the DNA-damage response, apoptosis, senescence, and angiogenesis. Recent investigations have identified PML as a regulator of metabolic pathways in stem cell compartments, including the hematopoietic system, and have provided researchers with new strategies for controlling stem cell maintenance and differentiation. Studies of PML in leukemia-initiating cells demonstrate that PML is also an essential component of their maintenance, which has drawn tremendous attention to PML from scientists in various stem cell fields. Here, we review research into PML and its associated pathways, including recent studies of PML as it relates to stem cell biology, as well as our finding that PML regulates fatty acid oxidation, which is essential to the maintenance of normal hematopoietic stem cells. We also discuss the therapeutic potential of controlling PML-associated pathways. In particular, we describe promising evidence for the use of arsenic trioxide in the treatment of chronic myeloid leukemia.
\end{abstract}

Keywords PML $\cdot$ Hematopoietic stem cells $\cdot$ Leukemia stem cells $\cdot$ Stem cell metabolism

F. Nakahara · C. N. Weiss · K. Ito $(\bowtie)$

Ruth L. and David S. Gottesman Institute for Stem Cell and Regenerative Medicine Research, Departments of Cell Biology and Medicine, Albert Einstein Cancer Center, Albert Einstein College of Medicine, Bronx, NY 10461, USA

e-mail: keisuke.ito@einstein.yu.edu

\section{Introduction}

The promyelocytic leukemia $(P M L)$ gene was first identified as a fusion partner of the human retinoic receptor alpha (RAR $\alpha$ ) in acute promyelocytic leukemia (APL). APL is categorized as the French-American-British subtype M3 of acute myelogenous leukemia (AML). More than $98 \%$ of APL patients harbor the $t(15 ; 17)$ translocation in leukemic cells $[1,2]$, generating the PMLRAR $\alpha$ fusion gene. PML-RAR $\alpha$ encodes an abnormal transcription factor that retains the RING finger, B boxes and at least two coiled coil (RBCC) domains of PML, and most portions of RAR $\alpha$ (Fig. 1) [3]. PML-RAR $\alpha$ exerts a dominant negative function on both of its parental proteins, each of which has various functions that contribute to myeloid differentiation, apoptosis, and DNA replication and repair [4]. When all-trans retinoic acid (ATRA) is administered, it promotes RAR $\alpha$-target gene transcription to overcome the differentiation block and induces the differentiation of leukemic cells in APL. On the other hand, arsenic trioxide $\left(\mathrm{As}_{2} \mathrm{O}_{3}\right)$ induces degradation of PML and the fusion protein encoded by $P M L-R A R \alpha$ through sumoylation, and promotes differentiation of leukemic cells, producing clinical remissions in APL (Fig. 1) [5]. Since the introduction of ATRA and $\mathrm{As}_{2} \mathrm{O}_{3}$ therapies for the treatment of APL, the overall survival rate has improved considerably. However, genetic mutations resulting in amino acid substitutions in the RAR $\alpha$ ligand binding domain or the PML-B2 domain of PML$\mathrm{RAR} \alpha$ have both been reported as molecular mechanisms underlying resistance to ATRA and $\mathrm{As}_{2} \mathrm{O}_{3}$ in refractory cases of PML [6].

PML proteins dimerize through the RBCC domains and then multimerize to form multi-protein sub-nuclear structures called PML-nuclear bodies (PML-NBs), which have 


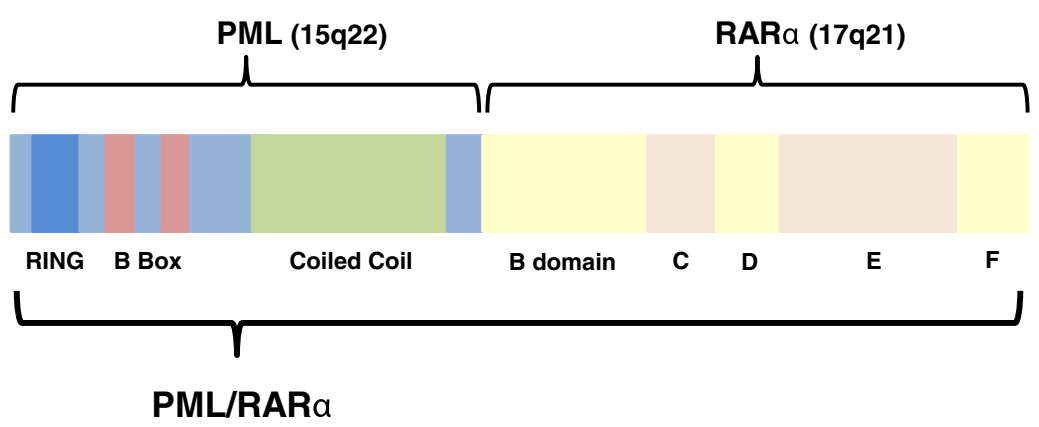

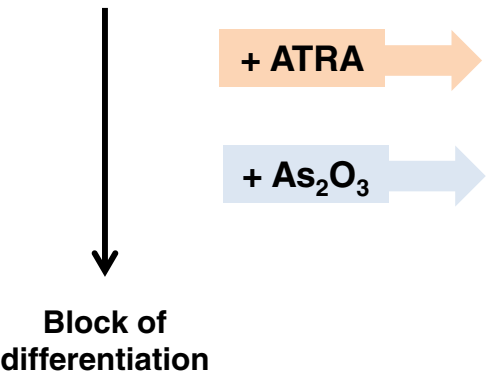

Fig. 1 Structure of the PML-RAR $\alpha$ fusion protein. $P M L-R A R \alpha$ encodes the RING finger, $\mathrm{B}$ boxes and at least two coiled coil (RBCC) domains of PML, and most portions of RAR $\alpha$ including the B through $\mathrm{F}$ domains. $\mathrm{B}$ domain, transcriptional activation domain (AF-1); $\mathrm{C}$ domain, DNA binding site which contains two $\mathrm{C}_{2} \mathrm{C}_{2}$ zinc finger motifs and RAR $\alpha$ binds to retinoic acid response element (RARE) located in the promoters of many genes through this domain; $\mathrm{D}$, hinge region; $\mathrm{E}$, transcriptional activation domain (AF-2); $\mathrm{F}$, function unknown. The PML-RAR $\alpha$ fusion protein induces a block of

three major biological functions. First, PML-NBs operate as a nuclear sponge for proteins, accumulating and releasing proteins under normal conditions, and sequestering foreign or misfolded proteins in pathological conditions. Second, PML-NBs form catalytic surfaces for the post-translational modification of proteins by sumoylation, ubiquitination, phosphorylation or acetylation. Third, PML-NBs serve as active sites for specific nuclear functions such as transcriptional regulation or heterochromatin formation. Through these functions, PML-NBs orchestrate biological processes, including DNA-damage response, apoptosis, senescence and angiogenesis in various tissues (Fig. 2a); [7, 8].

In this review, we alternate between discussions of normal homeostatic control and the deregulation that breeds malignancy to describe the mechanisms by which PML regulates the growth and proliferation of hematopoietic stem cells (HSCs) through the phosphatidylinositol 3-kinase (PI3-kinase)/Akt pathway. We also discuss how this pathway contributes to HSC energy metabolism, which is essential for HSC maintenance. Finally, we explore exciting evidence for the pharmacologic inhibition of PML in the treatment of chronic myelogenous leukemia (CML) and we propose directions for the future study of this very exciting protein.

\section{Promoting RARa-target gene transcription \\ Degradation of PML/RARa through sumoylation \\ Differentiation of leukemic cells}

hematopoietic differentiation. When all-trans retinoic acid (ATRA) is administered, it disassociates corepressor from the PML-RAR/ RXR complex and recruits coactivator, promoting RAR $\alpha$-target gene transcription to overcome the differentiation block and enables leukemic cells to differentiate in APL, leading to their exhaustion. On the other hand, arsenic trioxide $\left(\mathrm{As}_{2} \mathrm{O}_{3}\right)$ induces degradation of PML and the fusion protein PML-RAR $\alpha$ through sumoylation, and promotes differentiation of leukemic cells in APL

\section{PTEN antagonism of PI3-kinase/Akt/mTOR signaling in hematopoietic stem cells}

The PI3-kinase pathway promotes cell growth, proliferation and survival. PI3-kinase is activated following upstream signaling by growth factors, such as insulin or insulin-like growth factors; nutrients, especially amino acids; and environmental stress, including hypoxia [9, 10], which leads to the generation of phosphatidylinositol-3,4,5trisphosphate (PIP3) [10]. In turn, PIP3 activates Akt, which phosphorylates downstream substrates such as the tuberous sclerosis complex (TSC) and the forkhead box O (FoxO) family of proteins (Fig. 2b); [11]. Phosphorylation by Akt negatively regulates TSC, which leads to the activation of the mammalian target of rapamycin (mTOR) kinase [11]. The mTORC1 complex is a nutrient-sensitive multiprotein complex that is directly inhibited by rapamycin and promotes cell growth and proliferation by activating S6 kinase [11].

PI3-kinase signaling is inhibited by the phosphatase and tensin homolog (PTEN) tumor suppressor. PTEN dephosphorylates PIP3 [12] resulting in the suppression of Akt, thus reducing the growth and proliferative effects of this pathway (Fig. 2b). Conditional deletion of Pten leads to persistently enhanced self-renewal without exhaustion in 


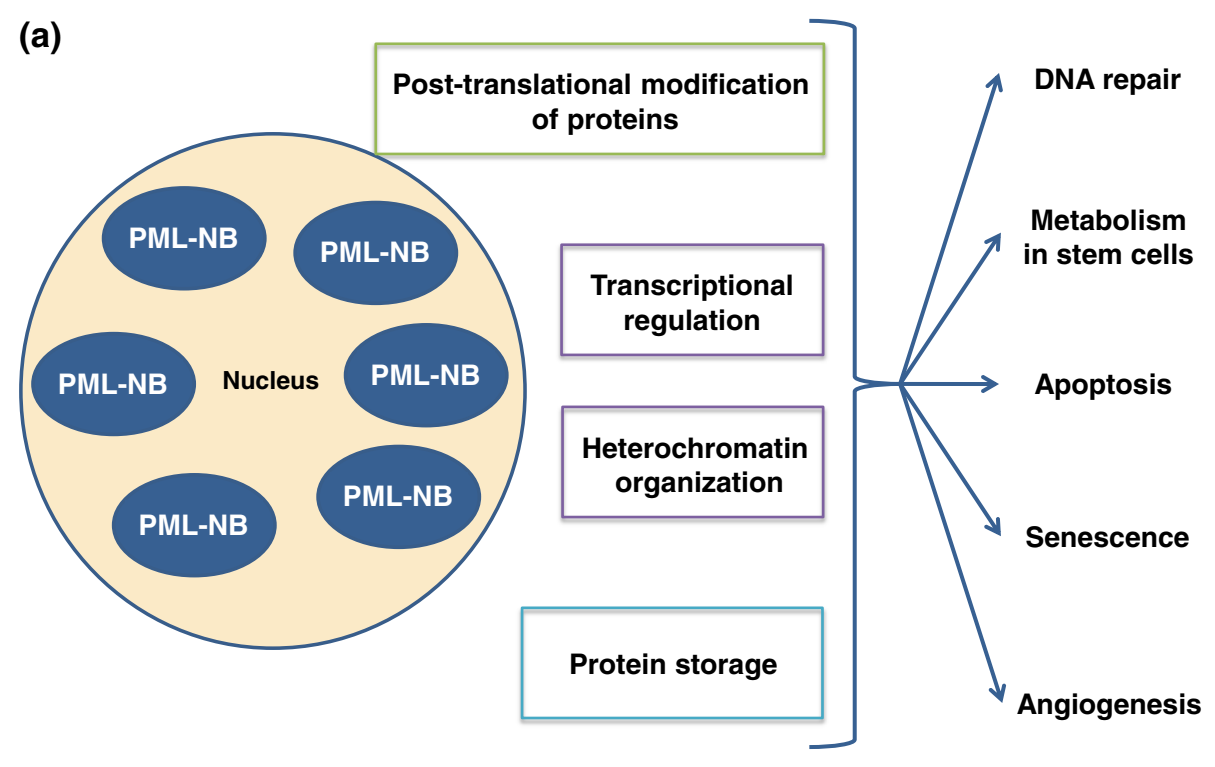

(b)

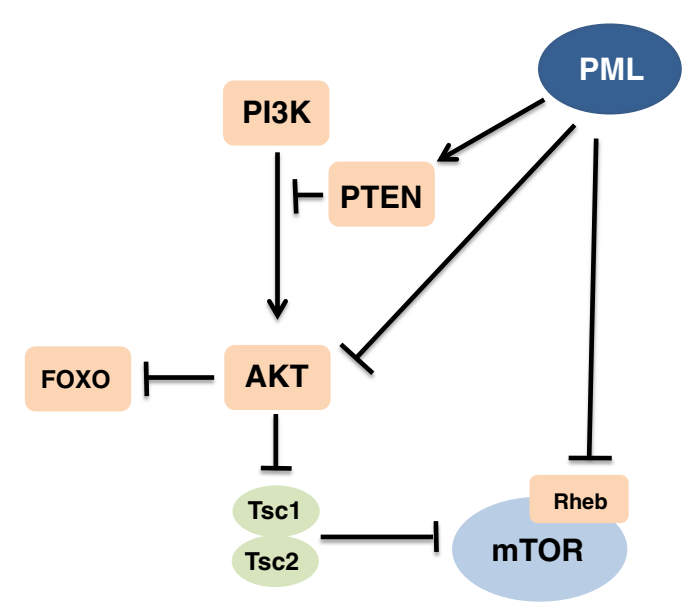

Fig. 2 The many functions of promyelocytic leukemia nuclear bodies and PML as a negative regulator of the PI3-kinase/Akt/mTOR pathway. a Promyelocytic leukemia nuclear bodies (PML-NBs) regulate diverse cellular functions, including the DNA-damage response, by storing and releasing checkpoint proteins and repair proteins following DNA damage; metabolism necessary for stem cell maintenance; cellular apoptosis and senescence; and angiogenesis. PML-NBs orchestrate these many functions through post-translational modification of proteins, including sumoylation, acetylation and phosphorylation; regulation of nuclear activities, such as transcription

neural stem cells [13]. In contrast, Pten deletion from adult HSCs leads to an increase in cell cycle entry and the rapid depletion of HSCs, yet causes the generation of transplantable leukemia-initiating cells (LICs) [14-16]. It has been shown that these effects are mostly mediated by mTOR, as they are abrogated by rapamycin treatment [14].

On the other hand, the inactivation of FoxO family transcription factors has also been implicated in the exhaustion of HSCs driven by Pten deletion. HSCs are reported to be vulnerable to the effects of oxidative stress and chromatin organization; and the identification and storage of proteins. b Aberrant activation of the PI3-kinase/Akt/mTOR pathway leads to the depletion of HSCs, which enter the cell cycle and are quickly exhausted. This pathway is negatively regulated by nuclear PML at several levels. PML maintains the PTEN tumor suppressor in the nucleus and inactivates phosphorylated AKT by recruiting an Akt phosphatase. PML also suppresses mTOR by inhibiting its association with Rheb, through physical interaction and accumulation of mTOR in the nucleus. Rheb, Ras homolog enriched in brain; TSC, tuberous sclerosis complex

[17]. When FoxO is localized to the nucleus, FoxO promotes the expression of enzymes that reduce reactive oxygen species (ROS). In Pten deletion, activated AKT phosphorylates FoxO proteins, restricting them to the cytoplasm and resulting in an increase of ROS levels [18]. In adult HSCs, the deletion of Foxo3a alone, or the deletion of Foxol, Foxo3 and Foxo4 together, leads to increased ROS levels, the depletion of HSCs and the loss of reconstitution capacity, which is rescued by treatment with the antioxidant N-acetyl-L-cysteine (NAC) [19, 20]. 


\section{PML regulation in normal hematopoietic stem cells}

Like PTEN, PML also serves as a tumor suppressor by negatively regulating the PI3-kinase/Akt/mTOR pathway at multiple levels. Trotman et al. [21] demonstrated that PML prevents cancer by inactivating phosphorylated AKT (pAKT) inside the nucleus by co-localizing the Akt phosphatase PP2a and pAKT in PML-NBs. Under hypoxic conditions, PML suppresses mTOR activity by inhibiting its association with Ras homolog enriched in brain (Rheb), a small GTPase, through physical interaction and accumulation of mTOR in the nucleus [22]. Additionally, Song et al. [23] reported that PML-NBs further repress the PI3kinase/Akt axis by promoting the accumulation of monoubiquitinated PTEN in the nucleus by opposing the activity of the deubiquitinating enzyme HAUSP (herpesvirusassociated ubiquitin-specific protease or USP7) through control of the adaptor protein DAXX (Fig. 2b). Considering the evidence for PML as a negative regulator of the PI3-kinase/Akt pathway, a pathway which leads to HSC exhaustion when activated, and the known role of the PML hybrid protein in hematological malignancies [14-16, 19, 20], we hypothesized that PML is essential in the maintenance of normal HSCs, as well as LICs.

We first found that the Pml expression is high in HSCs and declines as they differentiate. We also observed a greater number of PML-NBs in HSCs, as compared to committed cells [24]. Next, we showed that HSCs are reduced in older $\mathrm{Pml}^{-/-}$mice, and that $\mathrm{Pml}^{-/-}$HSCs have diminished repopulating capacity on serial transplantation. Colony forming assays, cell cycle analysis and examination of early time points in transplantation experiments revealed that $\mathrm{Pml}^{-{ }^{-}}$HSCs exhibit reduced quiescence, which likely contributes to their exhaustion. Thus, we concluded that PML is critical in the long-term maintenance of HSCs, though the precise molecular mechanisms underlying this role remained unclear.

\section{Metabolism in normal hematopoietic stem cells}

Most mammalian cells produce adenosine triphosphate (ATP) by mitochondrial oxidative phosphorylation, which utilizes glucose, glutamine or fatty acids. While mitochondrial ATP synthesis is the most efficient form of energy metabolism, it yields a damaging byproduct: reactive oxygen species (ROS).

HSCs are particularly vulnerable to the effects of oxidative stress, especially DNA damage, due to their longevity [17, 25, 26], and the ability of HSCs to self-renew and differentiate allows for accumulated damage to be spread throughout the entire hematopoietic system [27]. To avoid ROS generation and the associated damage, adult
HSCs generally maintain a slow-cycling state [28, 29]. We have previously discussed FoxO's role in the reduction of ROS in HSCs. Additionally, HSCs reside in the rather hypoxic bone marrow niche. Furthermore, glycolysis has been reported to be the main method of energy production in long-term HSCs (LT-HSCs) [28], and it is reasonable that they would utilize glycolysis, which is anaerobic and minimizes ROS production.

Simsek et al. [30] have reported that the transcription factors MEIS1 (Meis homeobox 1) and hypoxia-inducible factor $1 \alpha(\mathrm{HIF} 1 \alpha)$ are markedly enriched in LT-HSCs and upregulate the expression of glycolytic enzymes. In addition, Takubo et al. $[31,32]$ have shown that HIF1 $\alpha$ prevents oxidative phosphorylation in LT-HSCs by regulating pyruvate dehydrogenase kinases (PDKs) 2 and 4.

Additionally, there are reports that the highly conserved tumor suppressor LKB1 (liver kinase B1) is critical for the maintenance of energy homeostasis in HSCs through AMPK/mTORC1 dependent and independent mechanisms, which require further elucidation. Lkbl-deficient bone marrow cells exhibit mitochondrial defects, alterations in lipid and nucleotide metabolism, and depletion of cellular ATP [33-35].

Overall, it appears that LT-HSCs produce energy through glycolysis, thus avoiding ROS generation and maintaining their repopulating capacity.

\section{PML-PPAR $\delta$-FAO regulation in normal hematopoietic stem cells}

As previously mentioned, glycolysis has been reported to be the primary method of energy metabolism in HSCs [28, 30], and the tumor suppressor LKB1 is reported to be essential for the maintenance of HSCs through mitochondrial metabolism [33-35]. However, the contribution of lipid catabolism to HSC function remained unclear. Relating to fatty acid oxidation (FAO), peroxisome proliferator-activated receptor $\delta$ (PPAR- $\delta$ ), also known as PPAR- $\beta$, has been established as a crucial regulator of the transcriptional program underlying FAO [36, 37]. Thus, we investigated whether PPAR- $\delta$ and FAO could be relevant to HSC biology.

We first showed that PPAR- $\delta$ is highly expressed in $\mathrm{CD} 34^{\text {neg }} \mathrm{c}-\mathrm{Kit}^{+} \mathrm{Sca}^{+} \mathrm{Lin}^{\text {neg }}(\mathrm{KSL})$ cells, whereas PPAR- $\alpha$ and PPAR- $\gamma$ are not [38]. In vivo and in vitro assays using Ppard-conditional knockout KSL cells demonstrated that loss of Ppard profoundly affects quiescence and repopulating capacity of HSCs, while treatment with PPAR- $\delta$ agonists (GW-501516) increases the maintenance and repopulating capacity of HSCs. We also demonstrated that $P m l$-deficient HSCs have lower expression of PPAR- $\delta$ targets, and defects of $\mathrm{Pml}^{-/-}$HSCs were partially rescued 
Fig. 3 PML regulates asymmetric division and stem cell maintenance. PML induces deacetylation of PGC1 $\alpha$, which leads to the activation of peroxisome proliferatoractivated receptor (PPAR) signaling and the expression of fatty acid oxidation (FAO) genes. FAO increases asymmetric cell division in HSCs, enabling their selfrenewal and maintenance. When FAO is pharmacologically inhibited by etomoxir, HSCs undergo symmetric commitment and are exhausted

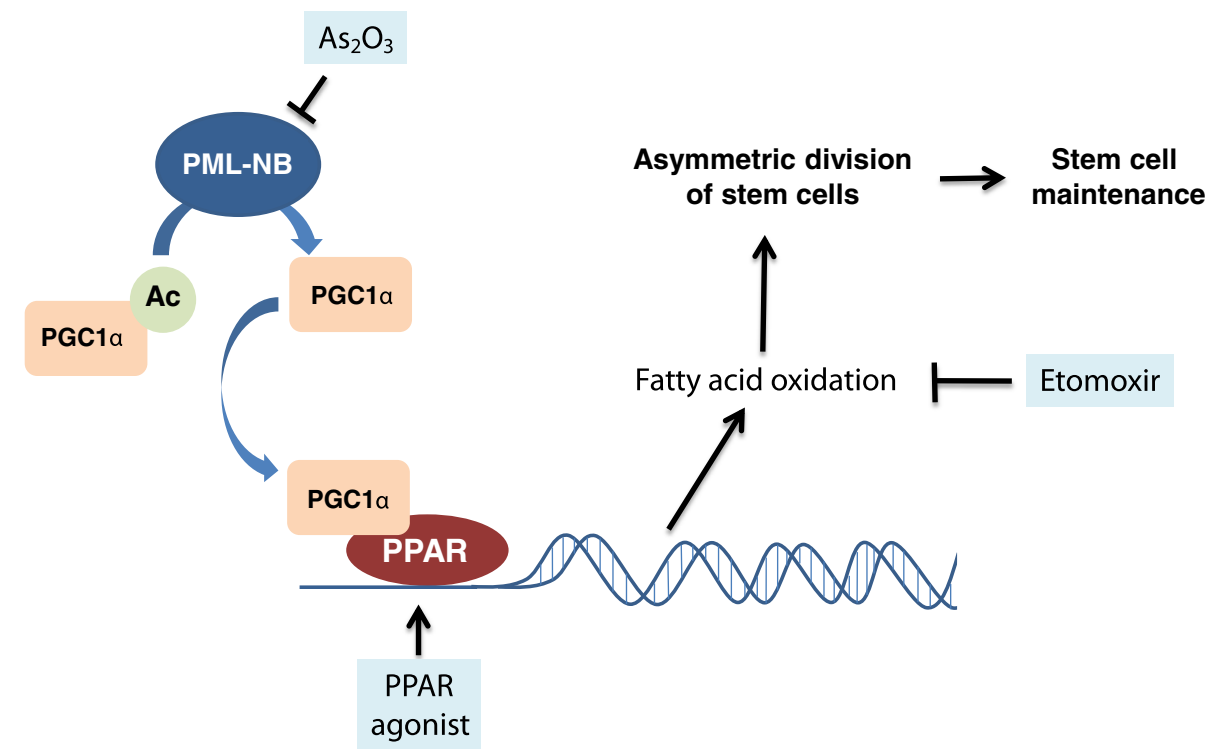

by PPAR- $\delta$ agonists. Pharmacological inhibition of FAO by etomoxir also reduced the repopulating capacity of HSCs [38]. Taken together, we concluded that the PMLPPAR- $\delta$-FAO pathway is critical to the self-renewal of HSCs.

We further hypothesized that the PML-PPAR- $\delta$-FAO pathway regulates asymmetric division of HSCs. Asymmetric cell division is a defining characteristic of stem cells that enables them to simultaneously self-renew and generate a committed progenitor [39]. Indeed, the deletion of Ppard or Pml, as well as inhibition of FAO, results in the symmetric commitment of HSC daughter cells, whereas PPAR- $\delta$ activation increases asymmetric cell division (Fig. 3) [38], suggesting that the PML-PPAR- $\delta$-FAO pathway regulates the decision between self-renewal and differentiation in HSCs.

\section{Metabolism in cancers}

Examining the dysregulation that occurs in cancer is also informative to the physiology of normal cells. The observation that malignant cells primarily utilize anaerobic glycolysis was first made by Otto Warburg in the early 20th Century [40]. Most cancer cells use enhanced cytosolic glycolysis as a means of energy production, even under normoxic conditions [41-43], hence the Warburg effect is used to monitor solid tumor progression with positron emission tomography (PET). Recent studies document a role for the master regulator Myc in stimulating glutamine catabolism, in part through the repression of microRNAs (miRs) miR-23a and miR-23b [44]. Additionally, aberrant activation of the PI3-kinase/Akt/mTOR pathway alters cellular activities and metabolism in various cancers [45].
Although the metabolism of glucose and glutamate by cancer cells has been a topic of thorough investigation, the important role of fatty acids in the growth and survival of cancer cells has only recently been recognized by researchers.

\section{Fatty acid metabolism in breast cancer}

In an earlier study, Schafer et al. [46] demonstrated that detachment of breast cancer cells from the extracellular matrix (ECM) results in an ATP deficiency due to the loss of ECM-dependent glucose transport. This ATP deficiency could be rescued by FAO, which was inhibited by detachment-induced ROS, when the cells were treated with the antioxidants N-acetyl-L-cysteine (NAC) or Trolox (a water-soluble Vitamin E derivative). Their experimentation provided a model for tumor survival in which cancer cells either stimulate ECM-independent glucose transport or mechanisms to reduce oxidative stress and restore FAO. This is consistent with a previous finding that cancer cells deprived of glucose maintain ATP production through FAO [47], and highlights the important role that FAO may play in cancer.

In an investigation of FAO in breast cancer, Carracedo et al. [48] reported that PML enhances FAO through PPAR signaling by inducing the deacetylation of PPAR- $\gamma$ coactivator $1 \alpha(\mathrm{PGC} 1 \alpha)$ by SIRT1. Further, they demonstrated that PML promotes ATP production and inhibits apoptosis in in vitro breast cancer models, whereas the effect was reversed with pharmacological inhibition of FAO. Gene set enrichment analysis (GSEA) in PML-expressing breast cancers showed a significant enrichment in activated PPAR signaling [48]. Additionally, immunohistochemical 
analysis of breast cancer biopsies revealed that PML is overexpressed in some breast cancers, particularly in the highly refractory triple-negative subset. Moreover, increased PML expression in breast cancer correlates with reduced time to recurrence [48].

These findings suggest that PML and FAO represent therapeutic targets in the treatment of breast cancer and raise the possibility that the metabolic functions of PML may be critical in other disease states, such as leukemias.

\section{PML regulation in leukemic stem cells}

Many critical mechanisms of HSC maintenance are also important in LICs, and so we investigated the role of PML in LICs. To probe the function of PML in leukemia, we first checked PML expression in human samples of CML. Strikingly, PML was highly expressed in blasts from CML patients [24]. And, remarkably, CML patients with low PML expression displayed higher complete molecular response $(\mathrm{CMR})$ and complete cytogenetic response (CCyR) compared to patients with high PML expression. Furthermore, patients with low PML expression showed greatly improved overall survival in CML. These results indicate that high levels of PML expression correlate with poor clinical outcomes in CML [24], which is contrary to the role of PML as a tumor suppressor in solid tumors.

Next, we transplanted $\mathrm{Pml}^{-1-}$ bone marrow transduced with $p 210^{B C R-A B L}$, which revealed that $P m l$ is essential in the maintenance of LICs as $P m l^{-/-}$LICs fail to develop CML-like disease after serial transplantation, in contrast to similarly transduced normal bone marrow [49]. In addition, inhibition of PML by $\mathrm{As}_{2} \mathrm{O}_{3}$ led to the reduction of quiescent LICs in bone marrow transduced with $p 210^{B C R-A B L}$ and cultured on stromal cells. Similarly, long-term cultureinitiating cell (LTC-IC) assays revealed the remarkable inhibitory effect of $\mathrm{As}_{2} \mathrm{O}_{3}$ on LIC maintenance. Moreover, $\mathrm{As}_{2} \mathrm{O}_{3}$ showed significant exhaustion of LICs in CMLtransplanted mice when paired with cytosine arabinoside (Ara-C) chemotherapy, and combination treatment led to complete cure in serially transplanted mice [24]. In progressive serial transplantations, $\mathrm{As}_{2} \mathrm{O}_{3}$ monotherapy became more effective than Ara-C monotherapy, highlighting the importance of the LIC in the maintenance of CML. Together, these findings demonstrate the essential role of PML in LIC biology, and suggest that PML-targeting could be a novel effective therapy in CML patients.

\section{Clinical implications}

Our study proposed a mechanism of HSC maintenance by the PML-PPAR- $\delta$-FAO pathway, which controls asymmetric division and self-renewal of HSCs. Deletion of Ppard or Pml, as well as inhibition of FAO, results in the symmetric commitment of HSC daughter cells, whereas PPAR- $\delta$ activation increases asymmetric cell division [38]. New strategies in the treatment of hematologic diseases may target this pathway to improve stem cell functions after bone marrow transplantation or to increase the recovery of HSCs after severe damage caused by chemotherapy or irradiation.

On the other hand, PML is also essential in the maintenance of LICs in CML and PML-targeting may prove an effective therapy in $\mathrm{CML}$ and other leukemias. $\mathrm{As}_{2} \mathrm{O}_{3}$, which targets PML for degradation [50], effectively induces quiescent LICs to enter the cell cycle leading to their exhaustion and the eradication of LICs in mice transplanted with CML [24]. The medicinal properties of arsenic have been described for thousands of years, with its anti-leukemic effects becoming evident in more recent centuries [51, 52]. Arsenic trioxide therapy is well tolerated and is now used routinely, in combination with ATRA, to treat low and intermediate risk APL [53-55]. Our promising results have led to the initiation of a clinical trial of $\mathrm{As}_{2} \mathrm{O}_{3}$, which would expand its use to the treatment of chronic-phase CML in combination with the tyrosine kinase inhibitor imatinib mesylate.

\section{Discussion and future directions}

Although there is clear evidence demonstrating the role of the PML-PPAR- $\delta$-FAO pathway in the control of HSC asymmetric division and maintenance, and the necessity of PML in the maintenance of LICs in CML, there are several issues to be elucidated in future studies.

While PML is essential in the maintenance of LICs in CML, it is not clear whether this effect relies on the FAO pathway downstream of PML. Additionally, the role of PML in other leukemias, such as acute myeloid leukemia, should be investigated.

Also, the physiologic role of PML in other stem cell populations should be the topic of further study. In nervous system development, loss of Pml causes differentiation failure and decreased cortical thickness [56]. Similarly, Pml deficiency leads to differentiation defects in the murine mammary gland, in both pregnant and virgin mice, which include aberrant gland morphology and disrupted lineage determination in bi-potent luminal progenitors [57]. Studies in mouse embryonic stem cells have demonstrated that the important stem cell regulator Oct4 and its activator Tr2 localize to PML-NBs, which supports a role for PML in the maintenance of the transcriptional profile of embryonic stem cells [58, 59]. Accompanying studies in human embryonic stem cells (hESCs) are lacking, but 
the highly variable morphology of PML-NBs in hESCs suggests that PML may play a crucial role in early human development [60]. Clearly, PML's role in normal stem cell physiology and homeostasis is an exciting and expanding area of study.

In summary, PML has diverse functions regulating biological processes such as DNA-damage response, apoptosis, senescence and angiogenesis in various tissues, and its role in stem cell maintenance is under investigation. Researchers have benefited from similarities in the mechanisms through which normal HSCs and LICs are maintained, which have allowed for insightful studies into the roles of FAO in stem cell physiology and in malignancy. New therapeutics may target metabolism to either enhance stem cell functions or to exhaust LICs. Further investigation into PML and its associated pathways, in both normal and pathologic conditions, may provide more pharmacologic targets and will shed light on the role of metabolism as a mediator of cell-fate.

In this review, we have outlined and discussed the details of PML and the PML-PPAR- $\delta$-FAO pathway on hematopoietic and leukemic stem cells. Further study into the similarities and differences in the function of PML between hematopoietic and leukemic stem cells is still needed and may provide novel and powerful strategies to target LICs in various types of leukemias.

Acknowledgments We are thankful to the Ito lab members for the comments and discussion on metabolism in stem cells. K.I. is supported by grants from the NIH (R00CA139009, R01DK98263). F.N. is supported, in part, by Uehara Memorial Foundation fellowship for Foreign Researchers in Japan and the Mochida Memorial Foundation fellowship for Foreign Researchers in Japan. C.W. is supported by an NIH MSTP training grant (T32-GM007288). Many original articles were omitted due to space limitations; for this, we apologize.

Conflict of interest The authors declare that they have no conflicts of interest.

\section{References}

1. Rowley JD. Identification of the constant chromosome regions involved in human hematologic malignant disease. Science. 1982;216:749-51.

2. de The H, Lavau C, Marchio A, Chomienne C, Degos L, Dejean A. The PML-RAR alpha fusion mRNA generated by the $t(15 ; 17)$ translocation in acute promyelocytic leukemia encodes a functionally altered RAR. Cell. 1991;66:675-84.

3. Melnick A, Licht JD. Deconstructing a disease: RAR $\alpha$, its fusion partners, and their roles in the pathogenesis of acute promyelocytic leukemia. Blood. 1999;93:3167-215.

4. Zhu J, Lallemand-Breitenbach V, de The H. Pathways of retinoic acid- or arsenic trioxide-induced PML/RAR $\alpha$ catabolism, role of oncogene degradation in disease remission. Oncogene. 2001;20: 7257-65. doi:10.1038/sj.onc. 1204852.

5. Lallemand-Breitenbach V, Jeanne M, Benhenda S, Nasr R, Lei M, Peres L, Zhou J, Zhu J, Raught B, de The H. Arsenic degrades PML or PML-RAR $\alpha$ through a SUMO-triggered RNF4/ ubiquitin-mediated pathway. Nat Cell Biol. 2008;10:547-55. doi:10.1038/ncb1717.

6. Tomita A, Kiyoi H, Naoe T. Mechanisms of action and resistance to all-trans retinoic acid (ATRA) and arsenic trioxide $\left(\mathrm{As}_{2} \mathrm{O}_{3}\right)$ in acute promyelocytic leukemia. Int J Hematol. 2013;97:717-25. doi:10.1007/s12185-013-1354-4.

7. Lallemand-Breitenbach V, de The H. PML nuclear bodies. Cold Spring Harb Persp Biol. 2010;2:a000661. doi:10.1101/cshper spect.a000661.

8. Bernardi R, Pandolfi PP. Structure, dynamics and functions of promyelocytic leukaemia nuclear bodies. Nat Rev Mol Cell Biol. 2007;8:1006-16. doi:10.1038/nrm2277.

9. Wullschleger S, Loewith R, Hall MN. TOR signaling in growth and metabolism. Cell. 2006;124:471-84. doi:10.1016/j.cell.2006. 01.016.

10. Yuan TL, Cantley LC. PI3 K pathway alterations in cancer: variations on a theme. Oncogene. 2008;27:5497-510. doi:10. 1038/onc.2008.245.

11. Inoki K, Li Y, Zhu T, Wu J, Guan KL. TSC2 is phosphorylated and inhibited by Akt and suppresses mTOR signalling. Nat Cell Biol. 2002;4:648-57. doi:10.1038/ncb839.

12. Maehama T, Dixon JE. The tumor suppressor, PTEN/MMAC1, dephosphorylates the lipid second messenger, phosphatidylinositol 3,4,5-trisphosphate. J Biol Chem. 1998;273:13375-8.

13. Gregorian C, Nakashima J, Le Belle J, Ohab J, Kim R, Liu A, Smith KB, Groszer M, Garcia AD, Sofroniew MV, Carmichael ST, Kornblum HI, Liu X, Wu H. Pten deletion in adult neural stem/progenitor cells enhances constitutive neurogenesis. J Neurosci. 2009;29:1874-86. doi:10.1523/jneurosci.3095-08.2009.

14. Yilmaz OH, Valdez R, Theisen BK, Guo W, Ferguson DO, Wu $\mathrm{H}$, Morrison SJ. Pten dependence distinguishes haematopoietic stem cells from leukaemia-initiating cells. Nature. 2006;441: 475-82. doi:10.1038/nature04703.

15. Zhang J, Grindley JC, Yin T, Jayasinghe S, He XC, Ross JT, Haug JS, Rupp D, Porter-Westpfahl KS, Wiedemann LM, Wu H, Li L. PTEN maintains haematopoietic stem cells and acts in lineage choice and leukaemia prevention. Nature. 2006;441: 518-22. doi:10.1038/nature04747.

16. Lee JY, Nakada D, Yilmaz OH, Tothova Z, Joseph NM, Lim MS, Gilliland DG, Morrison SJ. mTOR activation induces tumor suppressors that inhibit leukemogenesis and deplete hematopoietic stem cells after Pten deletion. Cell Stem Cell. 2010;7: 593-605. doi:10.1016/j.stem.2010.09.015.

17. Ito K, Hirao A, Arai F, Matsuoka S, Takubo K, Hamaguchi I, Nomiyama K, Hosokawa K, Sakurada K, Nakagata N, Ikeda Y, Mak TW, Suda T. Regulation of oxidative stress by ATM is required for self-renewal of haematopoietic stem cells. Nature. 2004;431:997-1002. doi:10.1038/nature02989.

18. Brunet A, Bonni A, Zigmond MJ, Lin MZ, Juo P, Hu LS, Anderson MJ, Arden KC, Blenis J, Greenberg ME. Akt promotes cell survival by phosphorylating and inhibiting a Forkhead transcription factor. Cell. 1999;96:857-68.

19. Miyamoto K, Araki KY, Naka K, Arai F, Takubo K, Yamazaki S, Matsuoka S, Miyamoto T, Ito K, Ohmura M, Chen C, Hosokawa K, Nakauchi H, Nakayama K, Nakayama KI, Harada M, Motoyama N, Suda T, Hirao A. Foxo3a is essential for maintenance of the hematopoietic stem cell pool. Cell Stem Cell. 2007;1: 101-12. doi:10.1016/j.stem.2007.02.001.

20. Tothova Z, Kollipara R, Huntly BJ, Lee BH, Castrillon DH, Cullen DE, McDowell EP, Lazo-Kallanian S, Williams IR, Sears C, Armstrong SA, Passegue E, DePinho RA, Gilliland DG. FoxOs are critical mediators of hematopoietic stem cell resistance to physiologic oxidative stress. Cell. 2007;128:325-39. doi:10. 1016/j.cell.2007.01.003.

21. Trotman LC, Alimonti A, Scaglioni PP, Koutcher JA, CordonCardo C, Pandolfi PP. Identification of a tumour suppressor 
network opposing nuclear Akt function. Nature. 2006;441:523-7. doi:10.1038/nature04809.

22. Bernardi R, Guernah I, Jin D, Grisendi S, Alimonti A, TeruyaFeldstein J, Cordon-Cardo C, Simon MC, Rafii S, Pandolfi PP. PML inhibits HIF-1 $\alpha$ translation and neoangiogenesis through repression of mTOR. Nature. 2006;442:779-85. doi:10.1038/ nature 05029 .

23. Song MS, Salmena L, Carracedo A, Egia A, Lo-Coco F, TeruyaFeldstein J, Pandolfi PP. The deubiquitinylation and localization of PTEN are regulated by a HAUSP-PML network. Nature. 2008;455:813-7. doi:10.1038/nature07290.

24. Ito K, Bernardi R, Morotti A, Matsuoka S, Saglio G, Ikeda Y, Rosenblatt J, Avigan DE, Teruya-Feldstein J, Pandolfi PP. PML targeting eradicates quiescent leukaemia-initiating cells. Nature. 2008;453:1072-8. doi:10.1038/nature07016.

25. Mandal PK, Blanpain C, Rossi DJ. DNA damage response in adult stem cells: pathways and consequences. Nat Rev Mol Cell Biol. 2011;12:198-202. doi:10.1038/nrm3060.

26. Weiss $\mathrm{CN}$, Ito $\mathrm{K}$. DNA damage response, redox status and hematopoiesis. Blood Cells Mol Dis. 2014;52:12-8. doi:10.1016/ j.bcmd.2013.08.002.

27. Ciccia A, Elledge SJ. The DNA damage response: making it safe to play with knives. Mol Cell. 2010;40:179-204. doi:10.1016/j. molcel.2010.09.019.

28. Suda T, Takubo K, Semenza GL. Metabolic regulation of hematopoietic stem cells in the hypoxic niche. Cell Stem Cell. 2011;9:298-310. doi:10.1016/j.stem.2011.09.010.

29. Rossi DJ, Jamieson CH, Weissman IL. Stems cells and the pathways to aging and cancer. Cell. 2008;132:681-96. doi:10. 1016/j.cell.2008.01.036.

30. Simsek T, Kocabas F, Zheng J, Deberardinis RJ, Mahmoud AI, Olson EN, Schneider JW, Zhang CC, Sadek HA. The distinct metabolic profile of hematopoietic stem cells reflects their location in a hypoxic niche. Cell Stem Cell. 2010;7:380-90. doi:10. 1016/j.stem.2010.07.011.

31. Takubo K, Nagamatsu G, Kobayashi CI, Nakamura-Ishizu A, Kobayashi H, Ikeda E, Goda N, Rahimi Y, Johnson RS, Soga T, Hirao A, Suematsu M, Suda T. Regulation of glycolysis by Pdk functions as a metabolic checkpoint for cell cycle quiescence in hematopoietic stem cells. Cell Stem Cell. 2013;12:49-61. doi:10. 1016/j.stem.2012.10.011.

32. Takubo K, Suda T. Roles of the hypoxia response system in hematopoietic and leukemic stem cells. Int $\mathrm{J}$ Hematol. 2012;95:478-83. doi:10.1007/s12185-012-1071-4.

33. Gan B, Hu J, Jiang S, Liu Y, Sahin E, Zhuang L, FletcherSananikone E, Colla S, Wang YA, Chin L, Depinho RA. Lkb1 regulates quiescence and metabolic homeostasis of haematopoietic stem cells. Nature. 2010;468:701-4. doi:10.1038/nature 09595.

34. Gurumurthy S, Xie SZ, Alagesan B, Kim J, Yusuf RZ, Saez B, Tzatsos A, Ozsolak F, Milos P, Ferrari F, Park PJ, Shirihai OS, Scadden DT, Bardeesy N. The Lkb1 metabolic sensor maintains haematopoietic stem cell survival. Nature. 2010;468:659-63. doi:10.1038/nature09572.

35. Nakada D, Saunders TL, Morrison SJ. Lkb1 regulates cell cycle and energy metabolism in haematopoietic stem cells. Nature. 2010;468:653-8. doi:10.1038/nature09571.

36. Michalik L, Auwerx J, Berger JP, Chatterjee VK, Glass CK, Gonzalez FJ, Grimaldi PA, Kadowaki T, Lazar MA, O’Rahilly S, Palmer CN, Plutzky J, Reddy JK, Spiegelman BM, Staels B, Wahli W. International Union of Pharmacology. LXI. Peroxisome proliferator-activated receptors. Pharmacol Rev. 2006;58: 726-41. doi:10.1124/pr.58.4.5.

37. Takahashi S, Tanaka T, Sakai J. New therapeutic target for metabolic syndrome: PPAR $\delta$. Endocr J. 2007;54:347-57.
38. Ito K, Carracedo A, Weiss D, Arai F, Ala U, Avigan DE, Schafer ZT, Evans RM, Suda T, Lee CH, Pandolfi PP. A PML-PPAR- $\delta$ pathway for fatty acid oxidation regulates hematopoietic stem cell maintenance. Nat Med. 2012;18:1350-8. doi:10.1038/nm. 2882.

39. Morrison SJ, Kimble J. Asymmetric and symmetric stem-cell divisions in development and cancer. Nature. 2006;441:1068-74. doi:10.1038/nature04956.

40. Warburg O. On the origin of cancer cells. Science. 1956;123: 309-14.

41. Jang M, Kim SS, Lee J. Cancer cell metabolism: implications for therapeutic targets. Exp Mol Med. 2013;45:e45. doi:10.1038/ emm.2013.85.

42. Koppenol WH, Bounds PL, Dang CV. Otto Warburg's contributions to current concepts of cancer metabolism. Nat Rev Cancer. 2011;11:325-37. doi:10.1038/nrc3038.

43. Mucaj V, Shay JE, Simon MC. Effects of hypoxia and HIFs on cancer metabolism. Int J Hematol. 2012;95:464-70. doi:10.1007/ s12185-012-1070-5.

44. Dang CV. Rethinking the Warburg effect with Myc micromanaging glutamine metabolism. Cancer Res. 2010;70:859-62. doi:10.1158/0008-5472.can-09-3556.

45. DeBerardinis RJ, Thompson CB. Cellular metabolism and disease: what do metabolic outliers teach us? Cell. 2012;148: 1132-44. doi:10.1016/j.cell.2012.02.032.

46. Schafer ZT, Grassian AR, Song L, Jiang Z, Gerhart-Hines Z, Irie HY, Gao S, Puigserver P, Brugge JS. Antioxidant and oncogene rescue of metabolic defects caused by loss of matrix attachment. Nature. 2009;461:109-13. doi:10.1038/nature08268.

47. Buzzai M, Bauer DE, Jones RG, Deberardinis RJ, Hatzivassiliou G, Elstrom RL, Thompson CB. The glucose dependence of Akttransformed cells can be reversed by pharmacologic activation of fatty acid $\beta$-oxidation. Oncogene. 2005;24:4165-73. doi:10.1038/ sj.onc. 1208622 .

48. Carracedo A, Weiss D, Leliaert AK, Bhasin M, de Boer VC, Laurent G, Adams AC, Sundvall M, Song SJ, Ito K, Finley LS, Egia A, Libermann T, Gerhart-Hines Z, Puigserver P, Haigis MC, Maratos-Flier E, Richardson AL, Schafer ZT, Pandolfi PP. A metabolic prosurvival role for PML in breast cancer. J Clin Invest. 2012;122:3088-100. doi:10.1172/jci62129.

49. Daley GQ, Van Etten RA, Baltimore D. Induction of chronic myelogenous leukemia in mice by the $\mathrm{P} 210 \mathrm{bcr} / \mathrm{abl}$ gene of the Philadelphia chromosome. Science. 1990;247:824-30.

50. Zhang XW, Yan XJ, Zhou ZR, Yang FF, Wu ZY, Sun HB, Liang WX, Song AX, Lallemand-Breitenbach V, Jeanne M, Zhang QY, Yang HY, Huang QH, Zhou GB, Tong JH, Zhang Y, Wu JH, Hu $\mathrm{HY}$, de The H, Chen SJ, Chen Z. Arsenic trioxide controls the fate of the PML-RAR $\alpha$ oncoprotein by directly binding PML. Science. 2010;328:240-3. doi:10.1126/science.1183424.

51. Antman KH. Introduction: the history of arsenic trioxide in cancer therapy. Oncologist. 2001;6(Suppl 2):1-2.

52. Cd K. Heavy metals and heavy-metal antagonists. In: Hardman JGGA, Limbird LE, editors. Goodman and Gilman's the pharmacological basis of therapeutics. New York: McGraw Hill; 1996. p. 1649-72.

53. Mathews V, George B, Lakshmi KM, Viswabandya A, Bajel A, Balasubramanian P, Shaji RV, Srivastava VM, Srivastava A, Chandy M. Single-agent arsenic trioxide in the treatment of newly diagnosed acute promyelocytic leukemia: durable remissions with minimal toxicity. Blood. 2006;107:2627-32. doi:10. 1182/blood-2005-08-3532.

54. Hu J, Liu YF, Wu CF, Xu F, Shen ZX, Zhu YM, Li JM, Tang W, Zhao WL, Wu W, Sun HP, Chen QS, Chen B, Zhou GB, Zelent A, Waxman S, Wang ZY, Chen SJ, Chen Z. Long-term efficacy and safety of all-trans retinoic acid/arsenic trioxide-based therapy 
in newly diagnosed acute promyelocytic leukemia. Proc Natl Acad Sci USA. 2009;106:3342-7. doi:10.1073/pnas.0813280106.

55. Iland HJ, Bradstock K, Supple SG, Catalano A, Collins M, Hertzberg M, Browett P, Grigg A, Firkin F, Hugman A, Reynolds J, Di Iulio J, Tiley C, Taylor K, Filshie R, Seldon M, Taper J, Szer J, Moore J, Bashford J, Seymour JF, Australasian L, Lymphoma G. All-trans-retinoic acid, idarubicin, and IV arsenic trioxide as initial therapy in acute promyelocytic leukemia (APML4). Blood. 2012;120:1570-80. doi:10.1182/blood-201202-410746 quiz 1752.

56. Regad T, Bellodi C, Nicotera P, Salomoni P. The tumor suppressor PML regulates cell fate in the developing neocortex. Nat Neurosci. 2009;12:132-40. doi:10.1038/nn.2251.

57. Li W, Ferguson BJ, Khaled WT, Tevendale M, Stingl J, Poli V, Rich T, Salomoni P, Watson CJ. PML depletion disrupts normal mammary gland development and skews the composition of the mammary luminal cell progenitor pool. Proc Natl Acad Sci. 2009;106:4725-30. doi:10.1073/pnas.0807640106.

58. Gupta P, Ho PC, Huq MM, Ha SG, Park SW, Khan AA, Tsai NP, Wei LN. Retinoic acid-stimulated sequential phosphorylation, PML recruitment, and Sumoylation of nuclear receptor TR2 to suppress Oct4 expression. Proc Natl Acad Sci USA. 2008;105:11424-9. doi:10.1073/pnas.0710561105.

59. Park SW, Hu X, Gupta P, Lin YP, Ha SG, Wei LN. SUMOylation of $\mathrm{Tr} 2$ orphan receptor involves PML and fine-tunes Oct4 expression in stem cells. Nat Struct Mol Biol. 2007;14:68-75. doi:10.1038/nsmb1185.

60. Butler JT, Hall LL, Smith KP, Lawrence JB. Changing nuclear landscape and unique PML structures during early epigenetic transitions of human embryonic stem cells. J Cell Biochem. 2009;107:609-21. doi:10.1002/jcb.22183. 